\title{
Capuchinos catalanes y colonización del Putumayo: Puerto Asís, Alvernia y Sucre (1905-1930**
}

\section{Resumen}

A principios del siglo XX el Estado colombiano y la Iglesia católica, decidieron implementar la estrategia de colonización en el Putumayo, a partir de la creación e imposición de un régimen de verdad, que se cimentó en la racialización, purificación, ocupación y propiedad, con el fin de lograr el asentamiento de migrantes nacionales y extranjeros, que coadyuvaran en la ampliación de la frontera de la civilización cristiana, la modernidad y la defensa de la soberanía. Bajo estas premisas, la Misión fundó 15 poblados en el Putumayo, durante la vigencia de la Prefectura Apostólica del Caquetá entre 1905 y 1930. Es así como a partir del análisis de los Informes de Misión publicados durante 1911 y 1926, incluidos algunos números de la Revista de Misiones que circuló entre 1925 y 1930, abordaré la historia de tres bastiones de los capuchinos catalanes: Puerto Asís (1912), Alvernia (1915) y Sucre (1916).

\section{Palabras clave}

Tesauro: misión religiosa, modernidad, colonización.

Autor: Putumayo, régimen de verdad, purificación.

Referencia bibliográfica para citar este artículo: Arteaga Montes, Giovany Paolo. "Capuchinos catalanes y colonización del Putumayo: Puerto Asís, Alvernia y Sucre (1905-1930)”. Anuario de Historia Regional y de las Fronteras 25.2 (2020): 47-68.

Fecha de recepción: 30/11/2019

Fecha de aceptación: 18 de abril del 2020

Giovany Paolo Arteaga Montes: candidato a Doctor en Antropología de la Universidad del Cauca. Magister en Historia por la Universidad del Valle. Especialista en Patrimonio Cultural y Turismo Sostenible por la Cátedra UNESCO, Buenos Aires. Especialista en Estudios Latinoamericanos del Centro de Estudios e Investigaciones Latinoamericanas (CEILAT). Coordinador de proyectos de la Fundación Mundo Espiral. Código ORCID: 0000-0002-6803-9513. Correo electrónico: arteagagiovanny@gmail.com.

*Este artículo es una versión extendida del capítulo III, del trabajo de investigación Almas para el cielo, ciudadanos para la república y territorio para la Nación: los caminos empleados por los capuchinos catalanes para alcanzar la civilización cristiana en el Putumayo, 1905-1930, tesis presentada a la Universidad del Valle, para obtener el título de Magíster en Historia.

La investigación contó con el apoyo del sistema de investigaciones del Banco de la República, seccional Pasto, instancia que facilitó el acceso y consulta de textos y documentos provenientes de la Red de Bibliotecas Luís Ángel Arango, que se extiende en varias ciudades de Colombia. 


\title{
Catalan Capuchins and Colonization of Putumayo: Puerto Asís, Alvernia and Sucre (1905-1930)
}

\begin{abstract}
At the beginning of the 20th century, the Colombian State and the Catholic Church, decided to implement the colonization strategy in Putumayo, based on the creation and imposition of a regime of truth, from the racialization, purification, occupation and property, with the goal to achieve the settlement of national and foreign migrants, who would contribute to the expansion of the frontier of Christian civilization, the modernity and the defense of sovereignty. Under these premises, the Mission founded 15 towns in Putumayo, during the validity of the Apostolic Prefecture of Caquetá, between 1905 and 1930. In this context, it is analyzed the Mission Reports published in the period of 1911-1926, including some issues of the Missions ' Magazine which circulated in 1925-1930, it will be addressed the history of three bastions of Catalan Capuchins: Puerto Asís (1912), Alvernia (1915) and Sucre (1916).
\end{abstract}

Keywords

Thesaurus: Religious Mission, Modernity, Colonization.

Author: Putumayo, Regime of Truth, Purification.

\section{Capuchinhos catalães e colonização de Putumayo: Puerto Asís, Alvernia e Sucre (1905-1930)}

\section{Resumo}

No início do século XX, o Estado colombiano e a Igreja Católica decidiram implementar a estratégia de colonização em Putumayo, a partir da criação e imposição de um "regime da verdade", baseado na racialização, purificação, ocupação e propriedade, a fim de alcançar a colonização com migrantes nacionais $e$ estrangeiros, que contribuirão para a expansão da fronteira da civilização cristã, da modernidade e da defesa da soberania. Sob essas premissas, a Missão fundou 15 assentamentos em Putumayo, durante o período da Prefeitura Apostólica de Caquetá, entre 1905 e 1930. É assim que, a partir da análise dos Relatórios de Missão publicados em 1911 e 1926, incluindo alguns números de na Revista de Misiones, que circulou entre 1925 e 1930, vou abordar a história de três bastiões dos capuchinhos catalães: Puerto Asís (1912), Alvernia (1915) e Sucre (1916).

\section{Palavras-chave}

Tesauro: Missão religiosa, modernidade, colonização.

Autor: Putumayo, regime de verdade, purificação. 


\section{Presentación}

Putumayo: Río que baja desde muy alto... Río que va hacia donde nace el sol

Días previos a finalizar el año 2011, viajé de Pasto (Nariño) a Sibundoy (Putumayo) en el suroccidente colombiano, poblado donde se ubica la comunidad indígena Kamsá y el Archivo Histórico de la Diócesis Mocoa-Sibundoy (AHDMS), sitio que cuenta con el registro del proceso misional capuchino catalán que se realizó en este territorio (espacio geográfico y habitantes humanos y no humanos) ${ }^{1}$ a inicios del siglo XX. Además, acudí a varias bibliotecas en Bogotá, hasta lograr reunir los 10 Informes de Misión que emitieron los religiosos entre 1911 y 1926, al igual que los 67 números de la Revista de Misiones que circularon entre 1925 y 1930, todo para conocer lo que fue la Prefectura Apostólica del Caquetá -de la que hizo parte el Putumayo- durante el periodo 1905-1930, la cual fue administrada de manera política, social, cultural, económica y ambiental, principalmente por los misioneros capuchinos catalanes, bajo el liderazgo de fray Fidel de Montclar. ${ }^{2}$

Dichos informes fueron compilados y redactados en su mayoría por el Prefecto Apostólico, con el objetivo de construir la diferencia negativa sobre el indígena (racialización), confirmar la labor misionera y demostrar la consonancia del accionar de la Iglesia con la visión del Estado, exponiendo cualitativa y cuantitativamente los avances y dificultades que superaba la Misión. Estos compilados se enviaban a la Santa Sede y se sustentaban en la Arquidiócesis de Bogotá ante el Gobierno, la Iglesia, la Junta Nacional de Misiones y personas destacadas de la sociedad civil, luego circulaban por las diócesis a nivel nacional, el Congreso, las órdenes religiosas y alcanzaban difusión internacional, en mayor proporción en España y Cataluña, debido a la procedencia de los religiosos. ${ }^{3}$

Por su parte, la Revista de Misiones brindaba un panorama de las misiones católicas en el mundo y en Colombia: Tierradentro, Magdalena, San Martín, San Andrés, Casanare, San Jorge, Pacífico, Goajira [Guajira], Arauca, Sarare, Urabá, Chocó, Caquetá y Putumayo. En ella, la Iglesia convocaba para que las personas se formen como misioneros; aparecen mártires, santos y beatos, sus acciones y exposiciones detalladas de los aportes económicos para las misiones realizados

\footnotetext{
${ }^{1}$ Bruno Latour, Nunca fuimos modernos: ensayos de antropología simétrica (Buenos Aires: Editorial Siglo Veintiuno, 2012) 153-156.

${ }^{2}$ Fraile capuchino que nació en Montclar, provincia de Lérida, Cataluña, el 25 de diciembre de 1867, vistió el hábito capuchino el 25 de diciembre de 1882 en Ibarra (Ecuador), estuvo en Colombia en 1891 y recibió la unción sacerdotal en 1892. Desarrolló su labor como superior y misionero en la comunidad de Cartago (Costa Rica) hacia 1901, fue nombrado Prefecto Apostólico del Caquetá en diciembre de 1904, cargo que desempeñó entre 1905 y 1929, año en que regresó a España debido a varios quebrantos de salud, falleció el 21 de marzo de 1934 en Arenys de mar, Barcelona. Véase: Revista de Misiones, III. 30, (1927): 173; Revista de Misiones, X. 110 (1934): 328-330; Fidel de Montclar, Por Colombia (Arenys de mar: Imprenta Tatjé, 1934) 4.

${ }^{3}$ Los misioneros del Putumayo publicaban en catalán en la Revista Catalunya Franciscana. Véase: Revista de Misiones, Año IV, No. 34, marzo de 1928.
} 
por países, departamentos y ciudades colombianas a través de diócesis, colegios, organizaciones e individuos mediante las Obras Pontificias: Propagación de la Fe, Santa Infancia y San Pedro Apóstol para la formación del clero indígena.

Los Informes se elaboraron anual o bienalmente y seguramente circularon entre personas con cierto grado de especialización, mientras que las revistas estaban dirigidas a cualquier público y se producían mensualmente. Los primeros se distribuyeron gratuitamente, las segundas gozaron de mayor tiraje ${ }^{4}$ y tenían un costo por suscripción o compra individual, ya que eran de obligatoria adquisición por mandato del Papa Pío XI, en la medida que no podían faltar en la casa de cada cristiano para apoyar a los misioneros y la patria.

Estos documentos se constituyeron en los medios eficaces que utilizaron los capuchinos catalanes para producir, poner en circulación e imponer un discurso sobre el Putumayo, a partir de las categorías, normas, estrategias y objetivos que perseguían la Iglesia y el Estado: evangelizar (imposición de la religión católica), modernizar (implementación del capitalismo) y colombianizar (consolidación del Estado-nación), que implicaba orientarse por la legislación colombiana, celebrar sus fiestas nacionales, ostentar sus símbolos patrios, hablar español y defender la soberanía.

En ellos se encontraban implícitas las relaciones entre pensamiento y acción, lenguaje y práctica, que construían posiciones y jerarquías: superior/ inferior, civilizado/salvaje, nosotros/otros. Así se cimentó un discurso victorioso del abnegado misionero sobre el territorio, en el que se negaban, invisibilizaban o se trataban de manera secundaria las disputas y conflictos por el poder político, junto a las negociaciones, pactos y alianzas entre los diversos actores, representados como sujetos pasivos: indígenas, colonos, comerciantes y funcionarios, lo que facilitaba el establecimiento de la hegemonía misionera.

Este discurso, al no ser neutral e "inocente", tenía claras intenciones de crear e imponer un régimen de verdad, ${ }^{5}$ es decir, un tipo de poder basado en el conocimiento que naturaliza una forma de ver, sentir y estar en el mundo, regula las relaciones sociales y por tanto, tiene consecuencias para aquellos que lo [enuncian] como para los que se encuentran "sujetos" a él. ${ }^{6}$ Aquí, tanto la observación como la descripción fueron fundamentales, para evaluar a partir del discurso evangelizador-modernizador la geografía, clima, fauna, flora, costumbres y organización de los indígenas, así se esbozó una etnografía o antropología que dio al régimen su validez y superioridad, al mezclar religión, ciencia y política.

\footnotetext{
${ }^{4}$ Del primer número de la Revista de Misiones se editaron 1500 ejemplares y al sexto se incrementó a 2300 que salían de las prensas de la Sociedad Editorial. Véase: Revista de Misiones, I. 8, (1926): 307.

${ }^{5}$ Stuart Hall, «The Rest and the West: Discourse and Power». En: Hall and Gieben (eds.), Formations of Modernity (London: Polity Press, 1992) 77-78. Traducción de Ana Díaz.

${ }^{6}$ En el texto, Hall acude a la palabra [usan], pero considero pertinente catalogarlo como [enuncian], en la medida que "unos" y "otros" utilizan el discurso como "régimen de verdad" y de alguna manera ambos están “sujetos” a él. Véase: Hall 107.
} 
Informes y Revistas que transmitían el discurso e imponían el régimen de verdad, legitimaron el accionar de los religiosos, difundieron la importancia de su labor "regeneradora" y motivaron la continuidad del apoyo eclesiástico, estatal y civil en el desarrollo de su obra de cristiandad. Dicha etapa conocida como "Regeneración", propuesta y apoyada por la "Hegemonía conservadora" entre 1886 y 1930, incluía formas de proceder hacia las zonas de frontera, donde las cordilleras marcaban el límite entre "civilización" y "barbarie", ya que en las "salvajes" llanuras no se practicaba la agricultura e imperaba la economía extractiva, las bonanzas y se encontraban "lejos de los auxilios de la Religión, la vigilancia de la República y aisladas de la vida civil", 7 haciéndolas susceptibles de apropiarse o entrar en disputa con los países vecinos.

Con la firma del Convenio de misiones de 1902 entre la Iglesia y el Estado colombiano, se buscaba patrocinar la llegada al país de órdenes católicas que evangelizaran, educaran, colonizaran y mantuvieran estas zonas de frontera para Colombia, mientras se restituía a la Iglesia algunos de sus bienes expropiados durante la desamortización de bienes de manos muertas. Fue así como varios investigadores se preocuparon por comprender los sucesos acaecidos en aquellos territorios a finales del siglo XIX y principios del siglo XX.

Análisis, que en concordancia con Misael Kuán Bahamón ${ }^{8}$ se pueden catalogar como eclesiásticos (apologéticos y exaltadores de la labor de la Iglesia), ${ }^{9}$ críticos (de tendencia marxista) ${ }^{10}$ y la nueva historia de las misiones (representaciones, relaciones y negociación cultural), que describe las misiones dentro de múltiples procesos en que evangelizadores, colonos, comerciantes, funcionarios e indios se transformaron desde el mismo momento en que entraron en contacto, aunque también se examinan las fuentes documentales bajo otras ópticas y se tienen en cuenta distintos elementos que pasaron desapercibidos.

En esta nueva perspectiva vinculé a Amada Carolina Pérez, ${ }^{11}$ que indagó en las misiones de La Guajira, Putumayo y Caquetá; por su parte, Camilo Mongua ${ }^{12}$ demuestra que entre 1845 y 1904 en la subregión del Putumayo-Aguarico, no se presentaba "abandono" o "ausencia" de estado, sino que se vivía bajo múltiples y complejas formaciones estatales o formas de gobierno particulares, donde comerciantes y misioneros asumían como

\footnotetext{
${ }^{7}$ Fidel de Montclar, Informe de las misiones en Colombia, obra de los misioneros capuchinos, de la Delegación Apostólica, del Gobierno y la Junta Arquidiocesana Nacional, Caquetá y Putumayo (Bogotá: Imprenta de la Cruzada, 1912) 4.

${ }^{8}$ Misael Kuán Bahamón, Civilización, frontera y barbarie: Misiones capuchinas en Caquetá y Putumayo, 1893-1929 (Bogotá: Editorial Universidad Javeriana, 2015).

${ }^{9}$ Aquí se incluye al capuchino Ramón Vidal, "Crítica histórica al libro de Víctor D. Bonilla «Siervos de Dios y Amos de indios»»", Separata Revista de Cultura Nariñense, 25 (1970): 37-127.

${ }^{10}$ Víctor Daniel Bonilla, Siervos de Dios y Amos de Indios: El Estado y la Misión Capuchina en el Putumayo (Bogotá: Editorial Stella, 1969).

${ }^{11}$ Amada Carolina Pérez Benavides, "Representaciones y prácticas en las zonas de Misión: los informes de los frailes capuchinos", Historia Cultural desde Colombia, Categorías y Debates (2012): 287-316.

${ }^{12}$ Camilo Mongua Calderón, Formaciones estatales en las fronteras amazónicas: religiosos, comerciantes e indigenas en el Putumayo-Aguarico, 1845-1904 (Tesis, Doctorado en Historia de los Andes, FlacsoEcuador, Quito, 2018).
} 
funcionarios, lo que generaba conflictos y alianzas entre ellos, las autoridades políticas y los grupos indígenas. También consulté investigadores locales, como Franco Romo Lucero, ${ }^{13}$ que profundizó en la construcción de la carretera entre Pasto y Mocoa; Guido Revelo, ${ }^{14}$ que narró la historia de Puerto Asís entre 1912-1960 y el antropólogo William Daza, ${ }^{15}$ que realizó un compilado de memorias de ascendientes de colonos nariñenses que llegaron al Alto Putumayo con los misioneros a inicios del siglo XX.

Al encontrar esta riqueza documental y bibliográfica, decidí aportar a la crítica y nueva historia de las misiones, con la realización de mi tesis de Maestría en Historia; Almas para el cielo, ciudadanos para la República y territorio para la Nación: los caminos empleados por los capuchinos catalanes para alcanzar la civilización cristiana en el Putumayo, 1905-1930. ${ }^{16}$ De esta manera, el artículo se relaciona con el capítulo III de esta investigación y se encuentra dividido en la presentación que incluye el contexto, elementos metodológicos y una reseña de estudios sobre la Misión del Putumayo; un segundo aparte vinculado al análisis histórico de tres casos de colonización implementados por los capuchinos en el Putumayo a inicios del siglo XX: Puerto Asís, Alvernia y Sucre, para finalizar con algunas reflexiones abiertas al diálogo en lugar de conclusiones cerradas.

Es necesario señalar, que la voz en este escrito inclinará la balanza hacia los misioneros, no porque los demás no tengan voz, sino porque los “Otros” aún aparecen ocultos entre los números, mapas, trazos, dibujos, fotografías y los espacios infinitos que existen entre las letras, palabras y párrafos de los documentos institucionales, ejercicio de visibilización necesario y urgente, que debe hacerse, pero que no es el objetivo de este artículo, ya que aquí, lo que pretendo es acercarme de manera histórica a la estrategia de colonización, proyectada e implementada por la Iglesia católica en el Putumayo. Aunque podría decirse que, en esa ausencia, los “Otros” están presentes, como parte constitutiva de las dos caras de la misma moneda.

Ahora sí, sea usted bienvenido a transitar por lo que algunos viajeros y religiosos de principios del siglo XX bautizaron como "El paraíso del diablo", ${ }^{17}$ nombre establecido por las consecuencias generadas por la violencia, esclavitud, tortura y muerte hacia los indios, ${ }^{18}$ producto de la "fiebre del caucho", la carencia de

\footnotetext{
${ }^{13}$ Franco Romo Lucero, Carreteras variantes (Pasto: sin editorial), 1990.

${ }^{14}$ Guido Revelo Calderón, Puerto Asis: una aproximación a su historia entre los años 1912 y 1960 (Bucaramanga: Editorial Sic, 2005).

${ }^{15}$ William Daza, Judith Jaramillo y otros, El Camino Viejo: Oralidad y Memoria Histórica, Municipio de San Francisco, Departamento del Putumayo (San Francisco: sin editorial, 2013).

${ }^{16}$ Arteaga Montes, Giovanny, Almas para el cielo, ciudadanos para la República y territorio para la Nación: los caminos empleados por los capuchinos catalanes para alcanzar la civilización cristiana en el Putumayo, 1905-1930 (Tesis, Maestría en Historia, Universidad del Valle, 2018).

${ }^{17}$ Así denominó el ingeniero norteamericano Walter Hardenburg, la situación que afrontaba el Putumayo debido a la explotación del caucho Hebea brasiliensi. Véase: "The Devil's Paradise", publicado en el periódico londinense Truth, 1909.

${ }^{18}$ En las fuentes documentales analizadas se utiliza indistintamente la palabra indio como término colonial peyorativo y el vocablo indígena, preferido por el discurso jurídico republicano. Véase: Nancy Appelbaum, Dibujar la Nación. La comisión corográfica en la Colombia del siglo XIX (Bogotá: Ediciones Uniandes,
} 
vías terrestres, el clima, la geografía, la no domesticación de la tierra y la existencia de naturalezas-culturas diversas, ${ }^{19}$ contrarias al evolucionado "ser humano moderno" al que se debía llegar, un paraíso que desde aquel inolvidable 20 diciembre de 2011 hasta hoy, me trasnocha, me envuelve y me obsesiona.

\section{Colonización del Putumayo a principios del siglo XX}

Una de las estrategias implementadas para lograr el "blanqueamiento"20 de la población indígena en el Putumayo fueron los procesos de colonización dirigidos y espontáneos, los primeros, promovidos por la Iglesia y el Estado, bajo unos requisitos morales católicos, junto a la respectiva planeación, acompañamiento y subvención para el desplazamiento y asentamiento de migrantes. Los segundos, se daban con la llegada de personas en busca de un mejor porvenir, a través de sus propios recursos y medios. Sin embargo, la Misión aseguraba que era la responsable de los dos procesos: "los unos, por haber sido llamados directamente por ella, y los otros porque entraron una vez se les entregó el paso expedito". ${ }^{21}$ Todo bajo el pretexto de ampliar la civilización cristiana y modernidad universal, mientras se fortalecía el mercado y la soberanía nacional.

Los misioneros expresaban que los recursos necesarios para el proyecto de colonización con familias nacionales eran cuantiosos, pero eran mucho menores a levantar, equipar y mantener ejércitos, dicha pauta permitiría prevenir la guerra con el Perú ${ }^{22}$ y afirmaría la soberanía del Estado colombiano en esta zona de frontera que se encontraba en litigio. Es así como en septiembre de 1911, la Junta Arquidiocesana Nacional de la Obra de las Misiones en Colombia, explicaba que era preciso contar con las siguientes premisas para lograr la inmigración:

1. Terminar caminos, talar y limpiar terrenos hasta dejarlos listos para la siembra, con el fin de trazar planos de poblados y construir chozas a manera de casas.

2. Entregar a cada colono una casa y 20 hectáreas de terreno limpio, herramientas, semillas y víveres durante seis meses. Aquel que permaneciera dos años en la colonia, adquiría propiedad de lo que recibió; si en este tiempo se iba, perdía todo derecho, y el Gobierno lo cedía a otro que desee establecerse en el lugar.

3. Se sugiere que los colonos no reciban auxilios en dinero, porque el Gobierno se exponía a perder las sumas invertidas.

\footnotetext{
Fondo de Cultura Económica, 2017) 185-192.

${ }^{19} \mathrm{El}$ concepto de naturalezas-culturas, no se retoma desde la modernidad como dos polos opuestos (naturaleza y cultura), sino como elementos coexistentes que implican lo humano y no humano. Véase: Bruno Latour.

${ }^{20}$ Blanqueamiento: categoría que reúne los procesos de evangelización, modernización y colombianización.

${ }^{21}$ Gaspar de Pinell, Las Misiones Católicas en Colombia, informes años de 1922 y 1923 (Bogotá: Imprenta Nacional, 1923) 90.

${ }^{22}$ Durante 1911 se presentaron varias escaramuzas entre Colombia y Perú en la región Amazónica de La Pedrera, sitio que se consolidó como parte de la soberanía colombiana a partir de la ratificación del Tratado Salomón-Lozano y la entrega física de los territorios el 17 de agosto de 1930.
} 
4. La Junta presupuestaba que entregaría 20 hectáreas y \$200 oro para talar y limpiar el terreno, $\$ 150$ oro se destinarían a la construcción de la casa, $\$ 50$ oro a la adquisición de herramientas y semillas, y $\$ 125$ oro para la alimentación durante seis meses, cantidades que sumaban $\$ 525$ oro por familia. ${ }^{23}$

Con relación a la colonización con familias extranjeras, la misma Junta advertía lo siguiente:

1. Por cuenta del Gobierno se prepararía el terreno, se levantarían casas y se entregarían víveres, herramientas y semillas, como estaba estipulado en el presupuesto para la colonización con familias nacionales, sumado a los gastos de viaje para llegar a la colonia.

2. Como los extranjeros que llegaban a colonizar el país se consideraban pobres y gente plebeya, el Gobierno celebraría contratos con empresarios o compañías de notoria probidad, comprometidas en buscar colonos católicos. Por esta razón se exigían los certificados civiles y eclesiásticos de donde eran procedentes, antes de trasladarlos al lugar designado.

3. Para que el gobierno no se aventurara a perder dinero en una empresa de la que todavía no había antecedentes en Colombia, se proponía comenzar la colonización con extranjeros en pequeña escala, aumentando gradualmente la suma destinada para tal efecto.

4. El proceso podía empezar trayendo 25 familias extranjeras, destinándoles un punto cercano a Mocoa, donde el clima no era ardiente. El presupuesto proyectado era de $\$ 525$ oro que se gastarían conforme lo establecía la colonización con nacionales, más $\$ 600$ oro adicionales, relacionados con los gastos de viaje desde el extranjero hacia Colombia, lo que sumaba $\$ 1125$ oro, multiplicado por 25 familias, se necesitaban entonces $\$ 28.125$ oro. $^{24}$

Con base en estas condiciones, se fundaron o refundaron varios pueblos, todos escalonados y estratégicos para la reducción indígena. La mayoría se ubicaron en el trayecto del Camino Nacional de Pasto al Río Putumayo que abrieron los capuchinos catalanes, asentamientos ubicados en sus diferentes unidades de paisaje: Andina, Piedemonte y Llanura Amazónica.

\footnotetext{
${ }^{23}$ Fidel de Montclar, Informe de las misiones católicas en el Caquetá y Putumayo, presentado al Excelentísimo Señor Doctor Don Francisco Ragonesi, Arzobispo de Mira y Delegado Apostólico en Colombia (Bogotá: Imprenta de La Cruzada, 1911) 25-29.

${ }^{24}$ Cabe resaltar que el proyecto de colonización dirigida con familias extranjeras no se llevó a cabo.
} 
Mapa 1. Unidades de paisaje del Putumayo y pueblos de principios del siglo XX.

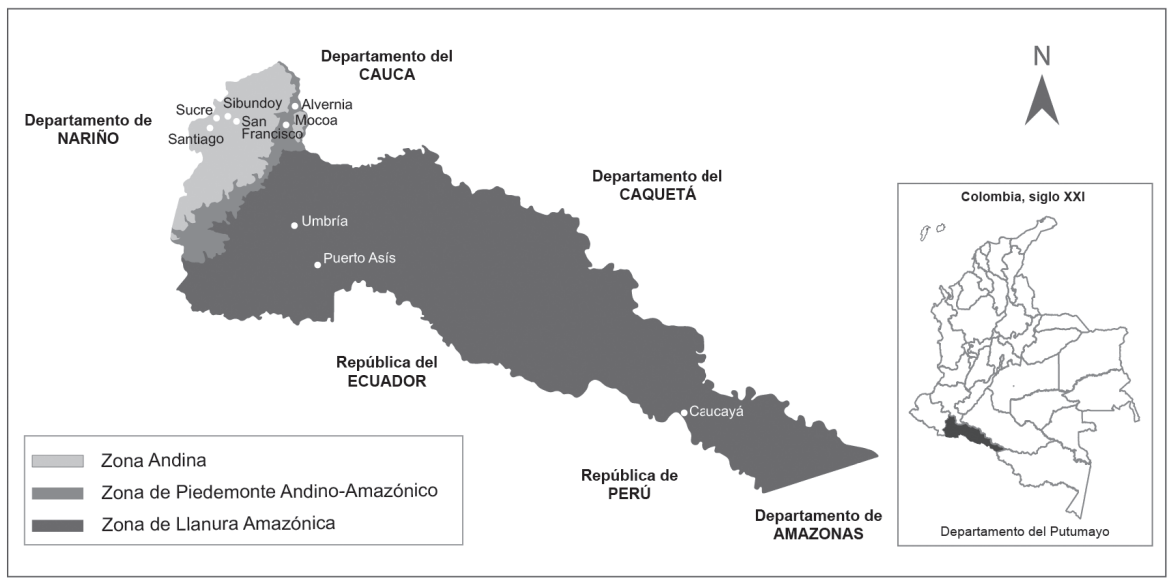

Fuente y adaptación: René Quintero M., 2018.

Tabla 1. Relieve, característica y predominancia o cercanía de las comunidades indígenas a los pueblos fundados o refundados por los misioneros en el Putumayo, 1905-1925.

\begin{tabular}{|c|c|c|c|c|}
\hline Relieve & Nombre & $\begin{array}{l}\text { Fundación / } \\
\text { refundación }\end{array}$ & Característica & $\begin{array}{c}\text { Predominancia } \\
\text { o cercanía de } \\
\text { indígenas al poblado }\end{array}$ \\
\hline & El Encano & $\begin{array}{l}1925 \\
\text { (se describe } \\
\text { desde 1910) }\end{array}$ & $\begin{array}{l}\text { Pueblo cerca de Pasto para } \\
\text { avanzar hacía el Putumayo, } \\
\text { ubicado en "El mar dulce" } \\
\text { (Laguna de La Cocha) }\end{array}$ & $\begin{array}{l}\text { Colonizado con } \\
\text { indios lagunas y } \\
\text { a dos leguas por } \\
\text { indios pejendinos, } \\
\text { ambos de Nariño }\end{array}$ \\
\hline \multirow{4}{*}{ Andino } & Santiago & ------ & $\begin{array}{l}\text { Pueblo de } 3000 \text { indígenas, el } \\
\text { primero del Valle de Sibundoy en } \\
\text { la dirección Pasto - Mocoa. }\end{array}$ & Inga \\
\hline & $\begin{array}{l}\text { Sucre } \\
\text { (actual } \\
\text { Colón) }\end{array}$ & 1916 & $\begin{array}{l}\text { Pueblo de blancos }{ }^{25} \text { en medio de } \\
\text { tres pueblos indígenas. }\end{array}$ & Inga \\
\hline & Sibundoy & 1906 & $\begin{array}{l}\text { Lugar de asiento de } 1500 \\
\text { indígenas. }\end{array}$ & Kamsá \\
\hline & $\begin{array}{c}\text { San } \\
\text { Francisco }\end{array}$ & 1905 & $\begin{array}{l}\text { Pueblo de blancos fundado por } \\
\text { la Misión en } 1904 \text { a } 6 \mathrm{~km} \text { de } \\
\text { Sibundoy, punto obligado para } \\
\text { salir a Mocoa. }\end{array}$ & Kamsá \\
\hline
\end{tabular}

\footnotetext{
${ }^{25}$ Blancos: individuos que hablan español, practican la religión católica y se orientan bajo los preceptos de las sociedades modernas-capitalistas, categoría que incluía europeos, mestizos, negros e indios.
} 


\begin{tabular}{|c|c|c|c|c|}
\hline Relieve & Nombre & $\begin{array}{l}\text { Fundación / } \\
\text { refundación }\end{array}$ & Característica & $\begin{array}{c}\text { Predominancia } \\
\text { o cercanía de } \\
\text { indígenas al poblado }\end{array}$ \\
\hline \multirow{3}{*}{$\begin{array}{l}\text { Piedemonte } \\
\text { Andino- } \\
\text { Amazónico }\end{array}$} & Mocoa & $1563 ?$ & $\begin{array}{l}\text { No fue refundada. Los misioneros } \\
\text { argumentaban que algún espíritu } \\
\text { maléfico se había empeñado } \\
\text { en acabarla, dos incendios } \\
\text { destruyeron la mayor parte de sus } \\
\text { casas antes de } 1914 \text {, razón por la } \\
\text { cual, decidieron reconstruirlas a } \\
10 \text { m de distancia entre sí. }\end{array}$ & Inga \\
\hline & Alvernia & 1915 & $\begin{array}{l}\text { Colonia antioqueña cerca de } \\
\text { Mocoa, en dirección al Cauca, } \\
\text { Huila y Caquetá, próxima a los } \\
\text { pueblos de indios de Condagua, } \\
\text { Yunguillo, Santa Rosa y } \\
\text { Descanse. }\end{array}$ & Inga \\
\hline & Limón & 1922 & $\begin{array}{l}\text { Población de indígenas que se } \\
\text { encontraba a cinco leguas de } \\
\text { Mocoa sobre el Río Caquetá. } \\
\text { Puerto que comunicaba con } \\
\text { las poblaciones de Quinoró, } \\
\text { Tresesquinas, Niña María, } \\
\text { Andaquí, Canelos, Florencia y } \\
\text { otros caseríos. }\end{array}$ & Inga \\
\hline \multirow{5}{*}{$\begin{array}{l}\text { Llanura } \\
\text { Amazónica }\end{array}$} & $\begin{array}{l}\text { San Bernardo } \\
\text { y Padua }\end{array}$ & 1914 & $\begin{array}{l}\text { Pueblos que servían de escala } \\
\text { entre Mocoa y Puerto Asís. }\end{array}$ & Inga \\
\hline & Umbría & 1912 & $\begin{array}{l}\text { Sitio donde terminaba el camino } \\
\text { de herradura entre Pasto y el Río } \\
\text { Putumayo, aquí el viajero podía } \\
\text { embarcarse en canoa para bajar } \\
\text { por el Río Uchipayaco hasta } \\
\text { llegar a Puerto Asís o recorrer } 13 \\
\text { leguas por trocha. }\end{array}$ & Inga \\
\hline & Puerto Asís & 1912 & $\begin{array}{l}\text { Puerto en la margen izquierda } \\
\text { del Río Putumayo, cerca del } \\
\text { límite con Ecuador, "metrópoli" } \\
\text { comercial y cultural, lugar } \\
\text { estratégico para la reducción de } \\
\text { indígenas, defensa de la soberanía } \\
\text { y la conexión con el mundo. }\end{array}$ & $\begin{array}{c}\text { kofán, siona, } \\
\text { huitoto, makaguaje, } \\
\text { koreguaje }\end{array}$ \\
\hline & San Miguel & 1916 & $\begin{array}{l}\text { Pueblo comunicado con Puerto } \\
\text { Asís, del mismo caserío se partía } \\
\text { por trocha para llegar al Aguarico } \\
\text { con el fin de conectar varias } \\
\text { poblaciones. }\end{array}$ & Kofán \\
\hline & $\begin{array}{l}\text { Caucayá } \\
\text { (actual } \\
\text { Puerto } \\
\text { Leguízamo) }\end{array}$ & 1920 & $\begin{array}{l}\text { Puerto sobre el Río Putumayo, } \\
\text { punto más cercano al Río Caquetá. }\end{array}$ & Huitoto \\
\hline
\end{tabular}

Fuente: Informes de Misión, 1911-1926. 
De esta manera, la fundación de colonias en aparentes espacios vacíos que realizaron los misioneros en el Putumayo durante el periodo 1905-1925 fue prolífera, más de 15 poblados en el mapa 2 así lo confirman.

No obstante, el mapa 3 permite comprender que la mayoría de las fundaciones se hicieron en lugares que eran y son parte de la territorialidad de los indígenas, no eran espacios vacíos como lo hizo creer el régimen de verdad misionero, eran lugares habitados por humanos y no humanos, con asentamientos que tenían estéticas totalmente diferentes a la urbe europea, con diversas relaciones de sus habitantes entre sí y el medio ambiente. Territorio que era necesario señalar negativamente y jerarquizar inferiormente para reducir o concentrar a los indios, al igual que permitía apropiar y colonizar con los blancos.

Mapa 2. "Camino Nacional de Pasto al Putumayo" y mapa de pueblos fundados o refundados por los misioneros en la Prefectura Apostólica del Caquetá.

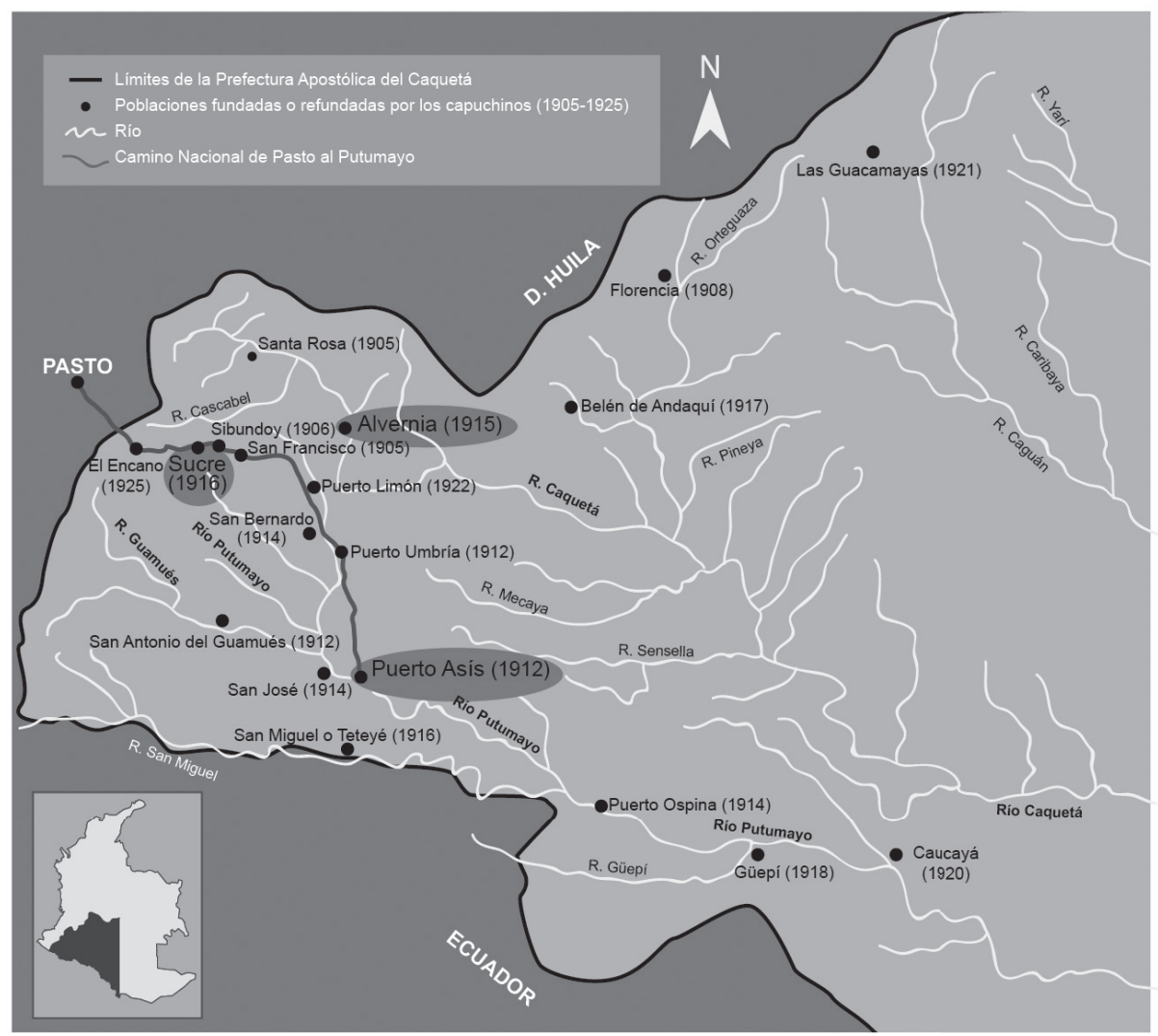

Fuente: Daza, Abel. "Excursiones apostólicas de los Misioneros Capuchinos Catalanes, Prefectura Apostólica del Caquetá, 1925”. // Misael Kuán Bahamón, "La Misión Capuchina en el Caquetá y el Putumayo 1893-1929" (Tesis, Maestría en Historia, Universidad Javeriana de Bogotá, 2013) // Adaptación del mapa con el camino entre Pasto y el Río Putumayo, junto a los pueblos de Sucre, Alvernia y Puerto Asís resaltados: René Quintero M., 2018. 
Mapa 3. Poblados y presencia indígena en el occidente del Caquetá y el Putumayo.

"Mapa étnic del Caquetá-Putumayo-Amazones".

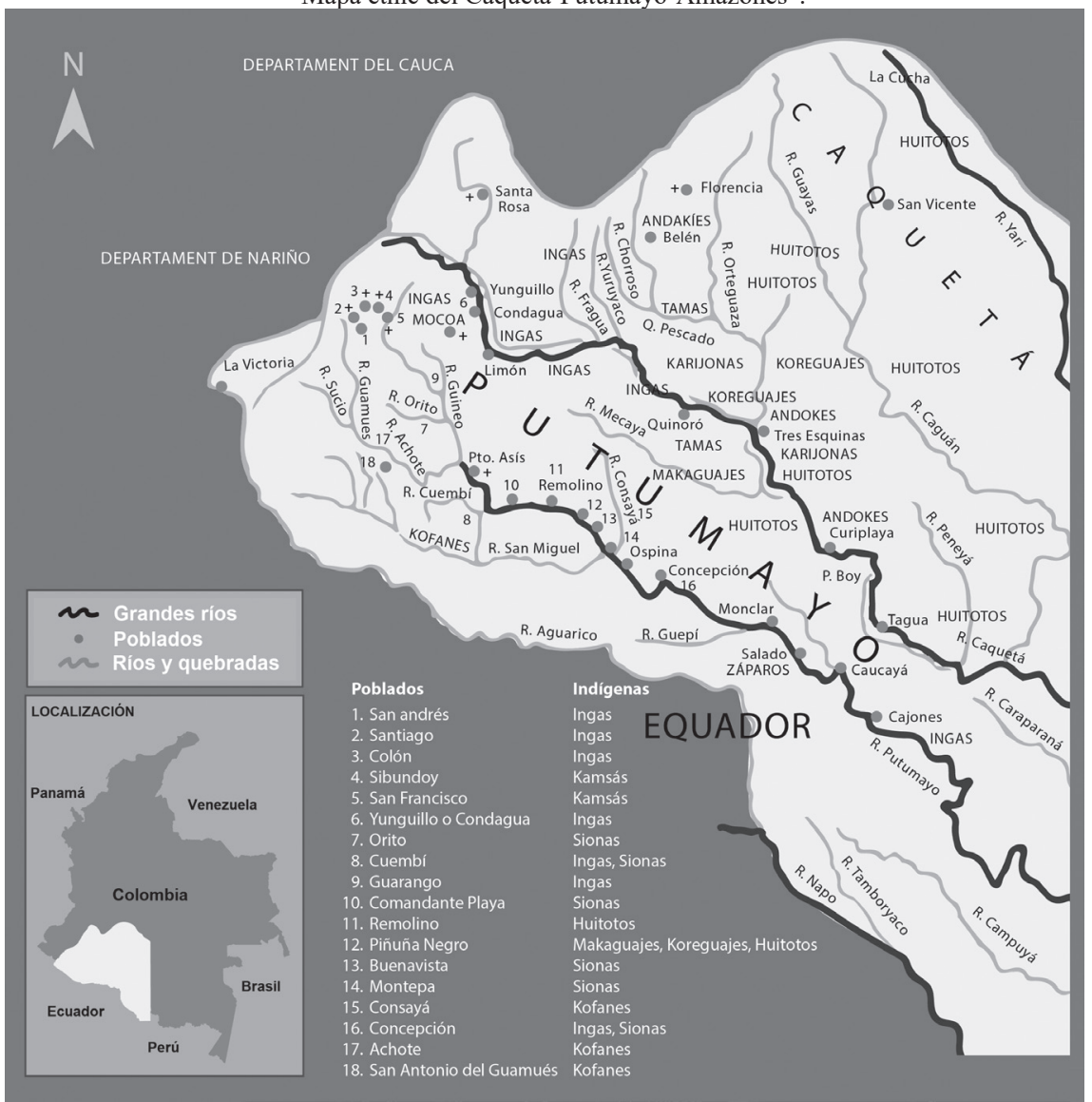

Fuente: "Mapa elaborado por los Misioneros Capuchinos Catalanes (cerca de 1928) 0-100-200 km". Elaboraron: Augusto Javier Gómez López y Elizabeth Riaño Umbarila, en: Putumayo: indios, misión, colonos y conflictos (1845-1970), (Popayán: Universidad del Cauca, 2010) //

Adaptación y detalle: René Quintero M., 2020.

\subsection{Puerto Asís}

Los capuchinos decidieron bautizar la colonia como Puerto, porque se encontraba en la margen izquierda del Río Putumayo, lugar de embarque de mercancías y pasajeros. Por su parte, Asís es el nombre del pueblo italiano de donde procedía San Francisco y la orden franciscana. La colonia se fundó el 3 de mayo de 1912 por los frailes Estanislao de Las Corts y el hermano Ildefonso de Tulcán.

Con relación a la importancia de esta colonia, Montclar recordaba los sucesos que ocurrieron en La Pedrera en 1911 e invitaba a los colombianos a defender el suelo patrio, no solo con las armas, sino con la implementación de la civilización cristiana en los lugares disputados con el Perú, legitimidad que posteriormente aseguraría el derecho, para certificar la posesión de la Amazonía hasta el Río Napo. 
Para esta fundación, los misioneros recorrieron diferentes parajes, selvas y riberas del Putumayo, solo después de un juicioso estudio escogieron el lugar donde se asentaría la colonia para satisfacer los designios de la Iglesia y la Nación, justo a $214 \mathrm{~km}$ de Pasto y $80 \mathrm{~km}$ de Mocoa, en plena Llanura Amazónica, donde el Río Putumayo era navegable a vapor hasta el Río Amazonas y el Océano Atlántico; por tanto, el Puerto también constituía un sitio estratégico como base de operaciones militares de Colombia.

Después de escoger el lugar y sortear las dificultades ambientales, al igual que la campaña de desmotivación a los peones para que no acompañen la Misión, se logró cumplir con la construcción de casas, tala de bosque y limpieza del suelo para la agricultura. Además, lograron proveer de víveres, herramientas y ropa a los trabajadores, ya que todo debían traerlo desde Pasto. Una vez se estableció el asentamiento, en las ceremonias religiosas era posible observar un lugar donde convergían blancos, casi todos de Nariño, algunos del Cauca y muy pocos del Tolima y Huila; indios, niños, mujeres y hombres vestidos de mil maneras y hablando distintas lenguas; gama cromática que se enriquecería con la llegada de la población negra, para conformar una especie de "metrópoli" en el Bajo Putumayo.

Se argumentaba que las riberas del Putumayo eran fértiles, su clima apacible y a corta distancia se divisaba la cordillera, consuelo para los que sentían nostalgia por la sierra y las tierras frías. ${ }^{26}$ Así los capuchinos afirmaban que, a través de este puerto, se podían alcanzar los mercados de Iquitos, Manaos y Belén del Para. Por consiguiente, proyectaban que Puerto Asís sería importante junto a Tumaco y Buenaventura en el Pacífico, al igual que Barranquilla en el Atlántico, carrera en la que llevaba ventaja Perú, con el control que ejercía Iquitos en la Hoya Amazónica.

Montclar constata la labor patriótica de los misioneros en Puerto Asís, al dar respuesta y hacer realidad la solicitud que emitió el 21 de enero de 1913 el General Lucio Velasco, Comandante de la $3^{\text {a }}$ División del Ejército Nacional, quien solicitaba que se exprese por escrito y en detalle, los edificios y terrenos cultivados que cedía la Misión a la fuerza pública acantonada en el Puerto. Cuatro días después, los religiosos emitían el acta de cesión de $215.000 \mathrm{~m}^{2}$ de terreno con cultivos de plátano, dos casas (una alta y otra baja) de columnas de chonta, de paredes de guadua (yaripa) y piso de madera aserrada, al igual que otras dos casas bajas con el mismo tipo de construcción, sin naves. ${ }^{27}$

La colonia tenía dos trapiches que llegaron de Estados Unidos y maquinaria de aserrar movida a vapor, del Ecuador se llevaron elementos para sembrar algodón que facilitarían el establecimiento de fábricas de tejidos, se estaban formando potreros con semillas de pasto pax-palum para el ganado. Hacia 1913, la población contaba con 210 individuos, más la fuerza militar; se esperaba que arribaran de Nariño 500 trabajadores para el fortalecimiento de la agricultura y la construcción de casas.

\footnotetext{
${ }^{26}$ De Montclar, Informe de las misiones católicas en el Caquetá y Putumayo, presentado al Excelentísimo Señor Doctor Don Francisco Ragonesi, Arzobispo de Mira y Delegado Apostólico en Colombia 132-139.

${ }^{27}$ De Montclar, "Informe de las misiones" 46-47.
} 
Si para la Misión, anteriormente era difícil la consecución de peones, ahora se notaba que existía simpatía por el Puerto, ya que contaba con hospital gratuito, orfelinato, escuelas, almacén de ropas, sastrería, fábrica de tejas, herramientas y medicamentos. ${ }^{28}$ Además, el alemán Rodolfo Evers dirigía dos cuadrillas de trabajadores, una de ellas encargada del cultivo y labores concernientes a la producción de caña de azúcar, y la otra ocupada en el montaje de una centrífuga y la construcción de hornos y edificios para un ingenio.

Para 1917, se visualizaba como un lugar importante para el tránsito de mercancías que se introducían desde Panamá, siguiendo la ruta de Tumaco, Barbacoas, Pasto y Mocoa hasta llegar a Puerto Asís, razón por la cual eran costosas. No obstante, los misioneros lograron llevar productos desde Iquitos a precios favorables, datos que hacían pensar en el alcance de esta colonia y el suroccidente colombiano, con el desarrollo de la navegación a vapor que comunicaría a Colombia con Europa y Norteamérica, sin pasar por Panamá. ${ }^{29}$

En 1918 se reconoce a Puerto Asís como el dique de contención, que si no se auxilia tiende a desaparecer; se expresa que antes contaba con número regular de soldados, quienes protegían la frontera y a la par dinamizaban el poblado, los cuales fueron suprimidos con el recorte presupuestal del Gobierno y la reducción del auxilio a la colonia en $50 \%$. Sumado a lo anterior, los pobladores no podían comercializar sus productos, en la medida que no se terminó el Camino Nacional hasta ese punto, ${ }^{30}$ vía que solo llegaría a Puerto Asís hasta el 20 de julio de 1931. Pese a estos inconvenientes, Asís se constituyó con el tiempo en un lugar importante para la defensa nacional, como lo demostró en el conflicto colombo-peruano (1932-1933), fue el puesto de avanzada para buscar la civilización del Bajo Putumayo y llegó a superar en importancia comercial a Mocoa, capital de la Comisaría.

\subsection{Alvernia}

En este punto acudiré a la propuesta de Neftalí Benavides ${ }^{31}$ sobre la colonización de Alvernia, nombre del monte italiano donde Francisco de Asís recibió los estigmas en 1224. Para lograr la inmigración, el Congreso de Colombia dictó una serie de Leyes $^{32}$ que cedieron al Departamento de Nariño terrenos baldíos del Putumayo, con el fin de llevar pobladores. Fue así como los misioneros recorrieron varios pueblos para invitar a los nariñenses, argumentando la fertilidad de las tierras del Piedemonte Andino-Amazónico, la bondad del clima y las óptimas facilidades para hacerse un mejor porvenir, ya que en Nariño los terrenos eran escasos.

\footnotetext{
${ }^{28}$ Fidel de Montclar, Informes sobre las misiones del Putumayo (Bogotá: Imprenta Nacional, 1916) 83-84.

${ }^{29}$ De Montclar, “Informes sobre las misiones” 121-122.

${ }^{30}$ De Canet de Mar, Benigno. Las Misiones Católicas en Colombia, labor de los misioneros en el Caquetá y Putumayo, Magdalena y Arauca, Informe, 1918-1919 (Bogotá: Imprenta Nacional, 1919) 33-34.

${ }^{31}$ Neftalí Benavides Rivera, "Putumayo... (un camino y una colonización)", Revista de Cultura Nariñense, 1. 8 (1969): 45.

${ }^{32}$ Leyes 51 de 1911, 106 de 1913 y 69 de 1914.
} 
La Ley 52 de noviembre de 1913, creó la Junta de Inmigración para la colonización de los territorios del Caquetá y Putumayo, instancia que se instaló en la ciudad de Pasto el 28 de enero de 1914 y que estuvo conformada por el Dr. Gonzalo Pérez (Gobernador del Departamento), fray Fidel de Montclar (Prefecto Apostólico del Caquetá y Putumayo) y Hermógenes Zarama (representante del Gobierno).

Mientras se motivaba a los habitantes del suroccidente colombiano para ir a estas tierras, fue comisionado por la Junta, José María Arango -ciudadano antioqueño de Sonsón, residente en Pasto- para que recorriera los pueblos de Antioquia, explicando las condiciones y ventajas de ser colono en el Putumayo. Posteriormente, Montclar viajó a Sonsón y recorrió varios pueblos para confirmar las bondades planteadas por Arango, entre las cuales se brindaría alimentación a las familias durante la travesía, hasta llegar al lugar de destino y durante seis meses más; se facilitarían mulas para el viaje, una por cada cuatro individuos; a cada familia se entregaría terreno para el cultivo, herramientas, semillas, casa o cincuenta pesos $(\$ 50.00)$ para su construcción; los inmigrantes deberían permanecer dos años constantes para adquirir derecho de propiedad.

Arango y Montclar lograron animar, convencer y acompañar a 130 antioqueños que fueron concentrados en Sonsón, ${ }^{33}$ de donde salieron rumbo al Putumayo el 28 de junio de 1915, así comenzaron una ruta difícil que duró cuarenta días, atravesando gran parte de Colombia con sus mujeres, hijos y equipaje hasta arribar a Pasto. La recepción que la capital de Nariño tributó a los visitantes fue multitudinaria y se constituyó en una verdadera fiesta; con carteles se invitó al pueblo para que saliera a recibirlos, Hermógenes Zarama - para aquel entonces Gobernador de Nariño- encabezó el acto solemne, acompañado del General Castellanos, los oficiales de la fuerza acantonada en Pasto, la Banda Militar y los secretarios de despacho.

A los ilustres visitantes se les proporcionó alojamiento en las escuelas y en varias casas. La prensa de Pasto, sin excepción, tributó grandes elogios a la Misión capuchina por la traída de la colonia antioqueña. Después de descansar unos días en la ciudad, los colonos continuaron con su marcha hacia el Putumayo y llegaron a Mocoa el 19 de agosto de 1915. Luego de recorrer otros días más las intrincadas selvas, 106 antioqueños fundaron Alvernia el 10 de septiembre de 1915.

Los colonos, al año siguiente de su salida de Sonsón, enviaron un comunicado desde Alvernia a fray Fidel de Montclar, en el que confirmaban que los puntos estipulados por la Junta de Inmigración fueron cumplidos. ${ }^{34}$ Ante los resultados positivos de esta primera avanzada, el Prefecto logró convencer a la Junta, en sesión del 15 de junio de 1916, para que, a través de un nuevo contrato por seis meses con José María Arango, entrara a Alvernia una segunda expedición con 150 antioqueños. En este empeño, la principal dificultad fue la falta de recursos económicos, así que la empresa recayó sobre la Misión.

\footnotetext{
${ }^{33}$ Los colonos provenían de Sonsón, La Ceja, El Tambo, Marinilla, Mesopotamia, Granada, Santuario, La Unión, El Peñol, El Carmen, Santo Domingo, San Roque, Abejorral y Argelia. Véase: Revelo Calderón 27.

${ }^{34}$ Neftalí Rivera 39-47.
} 
Los 147 antioqueños provenientes de Sonsón, llegaron a Pasto el 25 de febrero de 1917 después de sortear varios percances, ciudad en la que fueron recibidos con las cortesías acostumbradas. Luego de tres días, continuaron su camino e hicieron la entrada triunfal a Alvernia el 10 de marzo del mismo año. Los primeros colonos les dieron la bienvenida, entre arcos levantados y disparos de escopetas, discursos que nombraban a la Madre Patria (España), el Gobierno de Colombia y la Iglesia, iluminación, música y pólvora. Al día siguiente se celebró Tedéum y se dirigieron a recorrer las vegas de los ríos Ticuanayoy, Caquetá, Afán y Mocoa, para mirar terrenos y apropiárselos. Los primeros antioqueños se alegraron, porque los misioneros se comprometieron a comprar sus cultivos para proporcionar víveres y semillas a los recién llegados. Para 1919, la alegría cambió por tristeza; el poblado sufrió una borrasca y personas ajenas a él se dedicaron a difamar la Misión, consiguiendo que muchos abandonaran la colonia y se trasladaran a Pasto, de donde regresaron a su Departamento en estado de hambre. ${ }^{35}$

Sumado a los anteriores factores, se hacía difamación de los misioneros a través del periódico Orientación Liberal de Nariño, ante el cual, los capuchinos argumentaban que los compromisos con los migrantes se cumplieron, como lo aseguraban diversos informes. ${ }^{36}$ Los capuchinos afirmaban que, si los antioqueños deseaban abandonar la colonia, estarían dispuestos a llevar colonos de los pueblos de La Cruz y La Mesa del Departamento de Nariño, y que no habían hecho esto, por el temor que generaba el carácter de aquellos. Finalmente, Guido Revelo expone que la Iglesia declaró la colonia de Alvernia Distrito Nullius el 9 de mayo de 1921, la cual no prosperó por diferentes razones: la altísima temperatura del lugar, la deserción de un gran número de colonos, el arribo de contradictores de los religiosos y generadores de inconvenientes en la comunidad; al igual que la falta de vías en buen estado para comercializar los cultivos. ${ }^{37}$

\subsection{Sucre}

Los misioneros planificaron a Sucre como un pueblo que fundarían con nariñenses, para que ayudaran en el "blanqueamiento" de los indios de Santiago, Sibundoy y San Andrés, en la medida que para "civilizarse necesitan del contacto con el blanco; [...] sus usos y costumbres que, por malas que sean, son de civilizados, y por consiguiente menos repugnantes". ${ }^{38}$ Para los religiosos, esta nueva colonia sería uno de los centros más importantes del Putumayo, al constituirse en la competencia agrícola y comercial de Pasto, con un clima frío, óptimo para colonizar con nacionales y extranjeros.

\footnotetext{
${ }^{35}$ Benigno de Canet de Mar, Las Misiones Católicas en Colombia, labor de los misioneros en el Caquetá y Putumayo, Magdalena y Arauca, Informe, 1918-1919. 34.

${ }^{36}$ De Canet de Mar, Las Misiones Católicas en Colombia, labor de los misioneros en el Caquetá y Putumayo, Magdalena y Arauca, Informe, 1918-1919. 35-37.

${ }^{37}$ Revelo Calderón 28.

${ }^{38}$ Montclar, "Informes sobre las misiones" 26.
} 
La industria a desarrollar era la pecuaria, cuyos productos se comercializarían en las "Tierras del Oriente", ${ }^{39}$ Perú y Brasil; por estas razones, el fraile argüía que era necesario levantar prontamente los planos y que la Asamblea de Nariño ceda en beneficio de los colonos 10 hectáreas para cada uno. ${ }^{40}$ Así se emitió la Ordenanza número 85 de mayo 10 de 1916 para fundar Sucre, nombre que asumió por el Distrito al que pertenecieron los indígenas de la zona y se confirió a fray Fidel de Montclar como su fundador.

Sin embargo, el tribunal suspendió esta Ordenanza porque fue demandada por Luís Felipe Medina y cinco personas más, que habían usurpado tierras y no estaban interesadas en que se funde esta colonia, Montclar escribió a la magistratura y expresó que se tramite la nulidad para que puedan proseguir con su labor. Mientras esto se solucionaba, la Misión asumiría los gastos para que la obra no se paralice, apoyándose en la Junta de Baldíos y los fieles donantes del Departamento de Nariño. Ante esta situación, varios inmigrantes se desanimaron, pero el Prefecto publicó el 12 de octubre de 1916 un comunicado sobre la importancia de esta colonia y aseguraba que el Consejo de Estado había dictado sentencia favorable para que continúe la repartición de terrenos a los colonos.

Es así como se mantenía en pie la Ley 106 de 1913, que ordenaba la fundación y repartición de 10.000 hectáreas de terreno entre los colonos pobres. Esta legislación aparentemente evitaría el odio de clases en Nariño y protegería los terrenos cultivados por los indios en el Valle de Sibundoy, ya que se decía que los vendían a bajos precios, por amenaza, incluso, por un poco de licor. ${ }^{41}$ Según esta Ley, se dejaban 300 hectáreas de resguardo, 100 para beneficencia, 100 para la Iglesia, 100 para instrucción pública y 50 para que los hermanos Maristas enseñen agricultura; total: 650 hectáreas.

Pese a las demandas, en dos años de existencia (1918), la colonia había florecido. Esto lo comprueban los reportajes publicados por Garzón Nieto y Rodríguez Piñeres en El Nuevo Tiempo, los cuales exponen que el poblado tenía 200 casas, 2000 habitantes y que allí se trasladaría la sede principal de la Comisaría del Putumayo. ${ }^{42}$ Los misioneros afirmaban que si Sucre seguía creciendo de esta forma, se impediría el retroceso al salvajismo de los indios del Valle de Sibundoy y se explotarían mejor esos terrenos que fueron selva virgen. ${ }^{43}$ La proyección era importante, pero con el tiempo, el caserío no superó comercialmente a Pasto, el pueblo de Sibundoy tomó protagonismo en el Alto Putumayo y la capital de la Comisaría regresó a Mocoa.

\footnotetext{
${ }^{39}$ Nombre con el que se reconocía el Putumayo y la Amazonía occidental.

${ }^{40}$ Fidel de Montclar, Informes sobre las Misiones del Caquetá, Putumayo, Goajira, Casanare, Meta, Vichada, Vaupés, Arauca (Bogotá: Imprenta Nacional, 1917) 47-48.

${ }^{41}$ De Montclar, "Informes sobre las Misiones del Caquetá” 27-29.

42 De Canet de Mar 38.

${ }^{43}$ De Canet de Mar 39.
} 


\section{Reflexiones}

Así llegamos a la exposición de tres casos de colonización dirigida con nacionales en el Putumayo, ya que la propuesta de inmigración proyectada con familias extranjeras no se llevó a cabo, los pocos individuos que llegaron de lejanas latitudes, lo hicieron a través de una mezcla dirigida y espontánea.

Puerto Asís (1912) en la Llanura Amazónica, fue un caso exitoso, en la medida que se constituyó en punto estratégico para la concentración de indígenas, colonos y militares provenientes del suroccidente colombiano, con el fin de establecer y defender la soberanía, como lo hicieron durante el conflicto colombo-peruano, pero que no alcanzó a constituirse en el gran puerto navegable del Amazonas similar a Tumaco, Buenaventura o Barranquilla; por su parte, la fundación antioqueña de Alvernia (1915), en el Piedemonte Andino-Amazónico no prosperó, debido a múltiples factores, entre ellos, la falta de vías adecuadas para desarrollar la comercialización, así se declaró Distrito Nullius después de cinco años y algo más. Finalmente, Sucre (1916), colonia nariñense que se perfiló como eje administrativo de las "Tierras del Oriente" para superar a Pasto, jamás logró tal estatus, mientras que Sibundoy consiguió mayor relevancia en el Alto Putumayo.

De esta manera, gracias al recorrido histórico por estos tres bastiones de los capuchinos catalanes, es posible comprender cómo el poder eclesiástico de los misioneros se organizó y desarrolló a manera de formación estatal durante la vigencia de la Prefectura Apostólica del Caquetá entre 1905 y 1930, todo para alcanzar la civilización, modernización y colombianización del Putumayo, bajo el manto sagrado del catolicismo.

Fue así como el archivo para crear el discurso e implementar el régimen de verdad en el Putumayo durante la época de la Colonia y las primeras décadas del siglo $\mathrm{XX}$, provenía fundamentalmente de la Iglesia, y se constituyó con la biblia, pasando por bulas, encíclicas, carisma, Informes de Misión y Revista de Misiones, hasta relatos, artículos de periódicos o libros de geografía que elaboraron los religiosos, dirigentes del Gobierno, ingenieros, militares, geógrafos, médicos, viajeros, aventureros y comerciantes que se relacionaron o imaginaron la región.

Con todo, los Informes y Revista crearon la diferencia de manera narrativa y gráfica de las zonas de frontera y las misiones católicas en Colombia durante las primeras décadas del siglo XX, al igual que legitimaron el accionar de los religiosos, difundieron la importancia de su labor "regeneradora" y motivaron la continuidad del apoyo eclesiástico, estatal y civil en el desarrollo de su obra de cristiandad.

En este sentido, el pastor se visualizaba como aquel que gobierna abnegadamente el territorio de manera integral, un ser humilde y superior que gozaba de aparente inmunidad, que le permitía conducir su rebaño, conformado principalmente por indios catalogados de pasivos y "enfermos" por su cultura, a quienes era necesario imponerles un régimen de verdad, una serie de cuidados, 
una "regeneración" sustentada en el evangelio para salvar su cuerpo y alma; así se cumplió con la Misión que delegó Dios, tarea divina que consistía en planificar la blanca colonización, para constituir hombres evolucionados: civilizados, católicos y modernos, a partir de una mezcla entre religión, ciencia y política.

Económicamente, se expresaba que el apoyo del Estado colombiano era fluctuante e insuficiente, constituyendo una de las principales causas para que no se hiciera realidad lo planeado por los misioneros. Pero también se consideraba que la cultura de los indios no era compatible con el modelo capitalista que promovían los religiosos, mucho menos con el tiempo, el espacio, las necesidades del mercado y la explotación que debía hacerse de la naturaleza. Así podríamos decir que la tierra por la que supuestamente "vagaban los indios" permanecía vacía, terra nullius, como si "ellos" no existieran.

Paradójicamente, los indígenas están presentes en los documentos como protagonistas, ya sea simplificados como datos estadísticos, fotografías, narraciones o nomenclatura de los mapas, pero también se encuentran invisibilizados, infantilizados, caricaturizados, ridiculizados en su físico, costumbres, comportamientos y tienen voz, aunque por lo general no sea escuchada. Así, el territorio del Putumayo, aparentemente no estaba ocupado por humanos-modernos "fríos y maduros" que, eran capaces de transformar la materia prima en mercancías y explotar la tierra, pese a que contradictoriamente, los indios se miraban como la fuerza de trabajo ideal, adaptada al clima y la geografía, que había sido explotada bajo el modelo de economía extractiva y varias bonanzas.

En definitiva, la ocupación la relacionaban con la presencia de los indios, mientras que la propiedad, la ostentaban los blancos con la transformación del medio ambiente para el cultivo, la producción ${ }^{44}$ y la comercialización. En este orden de ideas, los colonos fueron los llamados a incrementar la propiedad y el capitalismo, mientras coadyuvaban para que desapareciera la ocupación ancestral, todo enmarcado en un tiempo que buscaba modernizar lo tradicional, como lo plantea Foucault, al expresar que en las relaciones de bio-poder es necesario "hacer vivir y dejar morir", ${ }^{45}$ en este caso, dejar morir al indígena del Putumayo, para que surja el supuesto humano moderno católico colombiano.

En este punto, debo resaltar que no pretendo plantear la inexistencia de la violencia en este proceso que se prolongó entre 1905 y 1930 hacia los indígenas, o el éxito total de la modernización o la ausencia de conflictos, alianzas, negociaciones y tácticas de los pobladores frente a las imposiciones institucionales. Lo que aquí presento, es la consolidación de una formación estatal a través de la delegación del poder y la diplomacia como lo plantea Camilo Mongua, antes de este periodo

\footnotetext{
${ }^{44}$ Elizabeth Povinelli, “¿Escuchan las rocas? La política cultural del trabajo aborigen australiano”, Cosmopolíticas: perspectivas antropológicas, (2013): 4-7.

45 Marisol de la Cadena, “¿Son los mestizos híbridos? Las políticas conceptuales de las identidades andinas". Formaciones de indianidad. Articulaciones raciales de mestizaje y nación en América Latina (Popayán: Envión Editores, 2007) 97.
} 
ejercida por los comerciantes y misioneros, ahora desarrollada principalmente por los religiosos, a partir de un discurso o régimen de verdad racializado, evangelizador y modernizante, que legitimó las maneras de sentir, pensar y actuar de los misioneros, funcionarios, colonos y la sociedad en sí, hacia unos territorios de frontera dentro de lo que se creía, era parte de la nación colombiana.

Allí los indios pervivieron, acudiendo a múltiples tácticas: se mezclaron, "jugaron", participaron, negociaron, estuvieron al margen y en algunas ocasiones aprovecharon las estrategias planteadas por los capuchinos, lo que llevó a que se vivieran diversas mixturas: la minga ${ }^{46}$ se combinó con la labor remunerada, la propiedad privada con la pertenencia comunitaria, el castellano con las lenguas nativas, las misas con los rituales ancestrales, el vestuario moderno con el tradicional, la relación naturalezas-culturas jamás desapareció.

Todo confirma que en esas representaciones y en aquellas estrategias institucionales, el hibrido sobrevivió, llevando la impronta de lo que en su momento fue el discurso de la Iglesia, el Estado y los "nosotros-complejos", como lo diría Marisol de la Cadena al retomar los planteamientos de Bruno Latour, cuando expresa que en la constitución de la modernidad latinoamericana, se pueden observar dos movimientos purificatorios: uno de ellos que fluyó a través de la fe y requirió de la separación entre cristianos/paganos y el otro que se perfiló a través de la razón e implicó la separación naturaleza/cultura, proceso que no se alcanzó en su totalidad y más bien, hizo que constantemente emanen híbridos ${ }^{47}$.

Hombres y mujeres que llevan como impronta lo que hizo en su momento el pastor misionero capuchino catalán con su visión del mundo; indígenas que, si algo aún conservan hasta hoy, como una de sus principales herencias y marca indeleble, es gustosamente su tipología racial indígena, aparentemente positiva, producto del discurso del Estado y la Nación, manifiesto en la Constitución de 1991 y la visión multiculturalista, tal vez, otra estrategia para que continúen como ocupantes, susceptibles de transformar sus tierras en propiedad, para que puedan ser apropiadas y explotadas por diversos actores.

\section{Bibliografía}

\section{Fuentes primarias}

\section{Archivos originales}

De Canet de Mar, Benigno. Las Misiones Católicas en Colombia, labor de los misioneros en el Caquetá y Putumayo, Magdalena y Arauca, Informe, 1918-1919. Bogotá: Imprenta Nacional, 1919.

\footnotetext{
${ }^{46}$ Minga: trabajo colectivo voluntario para alcanzar el beneficio común.

${ }^{47}$ De la Cadena 95.
} 
De Montclar, Fidel. Informe de las misiones católicas en el Caquetá y Putumayo, presentado al Excelentísimo Señor Doctor Don Francisco Ragonesi, Arzobispo de Mira y Delegado Apostólico en Colombia. Bogotá: Imprenta de La Cruzada, 1911.

De Montclar, Fidel . Informe de las misiones en Colombia, obra de los misioneros capuchinos, de la Delegación Apostólica, del Gobierno y la Junta Arquidiocesana Nacional, Caquetá y Putumayo. Bogotá: Imprenta de La Cruzada, 1912.

De Montclar, Fidel . Informes sobre las misiones del Putumayo. Bogotá: Imprenta Nacional, 1916.

De Montclar, Fidel . Informes sobre las Misiones del Caquetá, Putumayo, Goajira, Casanare, Meta, Vichada, Vaupés, Arauca. Bogotá: Imprenta Nacional, 1917.

De Montclar, Fidel . Por Colombia. Arenys de mar: Imprenta Tatjé, 1934.

De Pinell, Gaspar. Las Misiones Católicas en Colombia, informes años de 1922 y 1923. Bogotá: Imprenta Nacional, 1923.

Revista de Misiones. Año I, Número 8, Bogotá, sin editorial, enero de 1926.

Revista de Misiones. Año III, Número 30, Bogotá, sin editorial, noviembre de 1927.

Revista de Misiones. Año IV, Número 34, Bogotá, sin editorial, marzo de 1928.

Revista de Misiones. Año X, Número 110, Bogotá, sin editorial, julio de 1934.

\section{Fuentes secundarias}

\section{Libros}

Appelbaum, Nancy. Dibujar la Nación. La comisión corográfica en la Colombia del siglo XIX, Bogotá: Ediciones Uniandes, Fondo de Cultura Económica, 2017.

Bonilla, Víctor Daniel. Siervos de Dios y Amos de Indios: El Estado y la Misión Capuchina en el Putumayo, Bogotá: Editorial Stella, 1969.

Gómez López, Augusto Javier. Putumayo: indios, misión, colonos y conflictos (18451970), Popayán: Universidad del Cauca, 2010.

Kuán Bahamón, Misael. Civilización, frontera y barbarie: Misiones capuchinas en Caquetá y Putumayo, 1893-1929. Bogotá: Editorial Universidad Javeriana, 2015.

Latour, Bruno. Nunca fuimos modernos: ensayos de antropología simétrica. Buenos Aires: Editorial Siglo Veintinuno, 2012. 
Revelo Calderón, Guido, Puerto Asís: una aproximación a su historia entre los años 1912 y 1960. Bucaramanga: Editorial Sic, 2005.

Romo Lucero, Franco. Carreteras variantes. Pasto: sin editorial, 1990.

\section{Capítulos de libros}

De la Cadena, Marisol. “¿Son los mestizos híbridos? Las políticas conceptuales de las identidades andinas". Formaciones de indianidad. Articulaciones raciales de mestizaje y nación en América Latina, 2007.

Hall, Stuart. "The Rest and the West: Discourse and Power". En: Hall and Gieben (eds.), Formations of Modernity, London: Polity Press, 1992. Traducción Ana Díaz.

Pérez Benavides, Amada Carolina. "Representaciones y prácticas en las zonas de Misión: los informes de los frailes capuchinos". Historia Cultural desde Colombia, Categorías y Debates, 2012.

Povinelli, Elizabeth A. “¿Escuchan las rocas? La política cultural del trabajo aborigen australiano". Cosmopolíticas: perspectivas antropológicas, 2013.

\section{Artículos de revistas}

Benavides Rivera, Neftalí. "Putumayo... (un camino y una colonización)", Revista de Cultura Nariñense, 1. 8. (1969): 45.

Vidal, Ramón. "Crítica histórica al libro de Víctor D. Bonilla «Siervos de Dios y Amos de indios»”, Separata Revista de Cultura Nariñense. 25. (1970): 37-127.

\section{Tesis, ponencias, documentos y otros}

Arteaga Montes, Giovany Paolo. “Almas para el cielo, ciudadanos para la República y territorio para la Nación: los caminos empleados por los capuchinos catalanes para alcanzar la civilización cristiana en el Putumayo, 1905-1930”. Tesis, Maestría en Historia, Universidad del Valle, Cali, 2018.

Daza, William y otros. "El Camino Viejo: Oralidad y Memoria Histórica, Municipio de San Francisco, Departamento del Putumayo". Trabajo de investigación de la Alcaldía de San Francisco, 2013.

Mongua Calderón, Camilo. "Formaciones estatales en las fronteras amazónicas: religiosos, comerciantes e indígenas en el Putumayo - Aguarico, 1845-1904". Tesis, Doctorado en Historia de los Andes, Flacso-Ecuador, Quito, 2018). 